\title{
Correlation coefficient analysis in twelve gladiolus (Gladiolus hybrids Hort.) genotypes
}

\author{
Dhara Singh $^{1^{*}}$, Ashutosh Mishra ${ }^{1}$, Jitendra Singh $^{2}$, Vikas Kumar Khattik $^{1}$ and Balram Meena ${ }^{1}$ \\ ${ }^{1}$ Department of Floriculture and Landscaping, College of Horticulture and Forestry, Agriculture University, Kota, \\ Jhalarapatan, Jhalawar-326023 (Rajasthan), INDIA \\ ${ }^{2}$ Department of Fruit Science, College of Horticulture and Forestry, Agriculture University, Kota, Jhalarapatan, \\ Jhalawar-326023 (Rajasthan), INDIA \\ *Corresponding author. E-mail:dharasingh444@rediffmail.com
}

Received: May 22, 2016; Revised received: December 23, 2016; Accepted: April 11, 2017

\begin{abstract}
Study was undertaken to analyses the correlation co-efficient for twenty seven characters in twelve genotypes of gladiolus (Gladiolus hybridus Hort.) grown atthe Instructional Farm, Department of Floriculture \& Landscaping, College of Horticulture \& Forestry, Jhalarapatan, Jhalawar. Spike length had highly positive association with rachis length (rg:0.92, rp:0.88), floret diameter (rg:0.94, rp:0.0.74), spike diameter ( $\mathrm{rg}: 0.66, \mathrm{rp}: 0.50)$, duration of flowering (rg:0.71, rp:0.42), number of florets per spike (rg:0.89, rp:0.84), number of cormels per plant (rg:0.69, rp:0.65), diameter of corm (rg:0.48, rp:0.41), weight of corm ( $\mathrm{rg}: 0.44$, rp:0.40), weight of cormels per plant (rg:0.20, rp:0.19), size index of corms (rg:0.41, rp:0.38), florets remaining open at a time in vase (rg:0.56, rp:0.33). At both genotypic and phenotypic levels it had negative correlation with number of spikes per plot (rg:-0.56, rp:-0.48), number of corms per plant (rg:-0.72, rp:-0.50), number of corms per plot (rg:-0.60, rp:-0.54) and florets remaining unopened (rg:-0.39, rp:-0.37). It was observed that for most of the characters genotypic correlation coefficients were higher than phenotypic correlation coefficients.
\end{abstract}

Keywords: Characters, Coefficient Analysis, Correlation, Genotypes, Gladiolus

\section{INTRODUCTION}

Gladiolus (Gladiolus hybridus Hort.), a member of family Iridaceae. It is one of the important bulbous ornamental for cut flower. It occupies 4th place in international cut flower trade after Rose, Carnation and Chrysanthemum (Farhat, 2004). It is relatively easy to grow and is ideal for bedding and exhibition purposes. The spikes are used in spike arrangement, in bouquets and for indoor decorations.Popularity of this crop as a cut spike is increasing day by day because of its long keeping quality and exhaustive range of colours of the spikes. The study of interrelationship of various characters in the form of correlation is an important aspect in crop breeding. Knowledge of correlation studies helps the plant breeder to ascertain the real components of yield and provide an effective basis of selection (Ranchana et. al., 2015). High correlations between two characters indicate that selection for the improvement of one character leads to the simultaneous improvement in the other character depending upon the magnitude of association between them. The characters are considered to be independent when weak correlations exist between them and selection for a character may not affect the other. Gourishankarayya et al. (2005) and Archana et al. (2008) have reported for most of the characters genotypic correlation coefficients were higher than phenotypic correlation coefficients. Studies on genetic association is useful to ascertain the important component characters on which selection can be made (Singh and Kumar, 2008). Therefore, the present investigation was undertaken to estimate the magnitude and finding out correlations among important quantitative characters in the collected germplasm with respect to different morphological traits.

\section{MATERIALS AND METHODS}

The present investigation was conducted at the Instructional Farm, Department of Floriculture \& Landscaping, College of Horticulture \& Forestry, Jhalarapatan, Jhalawar, to identify important yield attributing characters for developing high yielding genotypes in gladiolus andto study performance of gladiolus under Jharlawarcondion.Simple correlations between different characters days to $50 \%$ sprouting, sprouts per corm, number of leaves/plant, plant height (cm), days to first spike emergence, days to first floret opening, days to $50 \%$ flowering, spike length $(\mathrm{cm})$, rachis length $(\mathrm{cm})$, spike diameter $(\mathrm{cm})$, floret diameter $(\mathrm{cm})$, duration of flowering, number of florets per spike, number of side spikes per plant, number of spikes per plot, number of corms per plant, diameter of 
corm (cm), weight of corm (g), weight of cormels per plant $(\mathrm{g})$, size index of corms $\left(\mathrm{cm}^{2}\right)$, vase life of spikes (days), floret remaining open at a time, days to wilting of basal floret and florets remaining unopened were worked out. Correlation coefficients were tested by referring to correlation values (Fisher and Yates, 1963). Simple correlation coefficient pertaining to the phenotype and genotype for characters were computed as per method as suggested by Singh and Chaudhary (1979).

\section{RESULTS AND DISCUSSION}

In the present study, it was observed that for most of the characters have been presented in Table 1 and 2 genotypic correlation coefficients were higher than phenotypic correlation coefficients for most of the characters, indicating a strong inherent association between various characters and were masked by environmental component with regard to phenotypic expression. Similar results were obtained by Singh (2009) in antirrhinum and Pattanaik et al. (2015) in gladiolus. A positive correlation were observed for days to $50 \%$ sprouting with plant height (rg:0.45, rp:0.16), spike length (rg:0.19, rp:0.07), rachis length (rg:0.33, rp:0.14), floret diameter (rg:0.47, rp:0.15), duration of flowering (rg:0.49, rp:0.02), number of floret per spike (rg:0.43, rp:0.18), diameter of corm (rg:0.63,rp:0.24), weight of corm (rg:0.45,rp:0.20), size index of corms (rg:0.94, rp:0.48) and vase life of spikes (rg:0.38, rp:0.04). It had negative correlation with number of leaves per plant (rg:-0.31, rp:-0.23), days to first spike emergence (rg:-0.47, rp:-0.22), number of side spikes per plant (rg:-0.54, rp:-0.34), number of cormels per plant (rg:-0.30, rp:-0.16) and florets remaining open at a time in vase (rg:-0.13, rp:0.02).The variation in days to sprouting of corm amongst various varieties might be due the genotypic differences that could have contributed to different hormonal levels, especially of gibberellins and abscisic acid in the corm sprouting in different hormonal levels, especially of time required for sprouting. These results in agreement with the results of Swain et al. (2008) in gladiolus and Mandal et al. (2013) in tuberose.Plant height highly positive association at both phenotypic and genotypic levels with size index of corms (rg:0.94, rp:0.48), diameter of corm (rg:0.63, rp:0.24), duration of flowering (rg:0.49, rp:0.02), floret diameter (rg:0.49, rp:0.15), days to first floret opening (rg:0.36, rp:0.18), days to first spike emergence (rg:0.37, rp:0.24) and floret diameter (rg:1.00, rp:0.67). Maurya et al., (2011) revealed that plant height exhibited highly significant and positive correlation with weight of corm, corm diameter, rachis length and number of leaf per plant. Number of florets per spike has shown positive relationship with number of cormels per plant (rg:0.37, rp:0.35), diameter of corm (rg:0.40, rp:0.32), weight of corm (rg:0.37, rp:0.32), weight of cormels per plant (rg:0.13, rp:0.12), size index of corms (rg:0.53, rp:0.48), vase life of spikes (rg:0.47, rp:0.39), florets remaining open at a time in vase (rg:0.40, rp:0.26). It had negative correlation at both genotypic and phenotypic level with number of side spikes per plant (rg:-0.05, rp:-0.03), number of corms per plant (rg:-0.89, rp:-0.56), number of spikes per plot (rg:-0.71, rp:-0.58), number of corms per plot (rg:-0.73, rp:-0.62), and florets remaining unopened (rg:-0.41, rp:-0.38) (Nazir et al.,2003). The variation in number of florets per spike might be due to their genetic make-up that could have also been influenced by the environmental condition (especially temperature and photoperiod) prevailed during trial period (Lepcha et al., 2007). Number of leaves per plant has shown highly positive correlation with plant height (rg:0.76, rp:0.61), days to first spike emergence (rg:0.67, rp:0.0.47), days to first floret opening (rg:0.71, rp:0.32), days to 50\% flowering (rg:0.54, rp:0.46), spike length (rg:0.79, rp:0.68), rachis length (rg:0.60, rp:0.51), spike diameter (rg:0.46, rp:0.33), floret diameter (rg:0.69, rp:0.42), duration of flowering (rg:0.54, rp:0.31), number of florets per spike (rg:0.62, rp:0.46), number of side spikes per plant (rg:0.23, rp:0.21), number of cormels per plant (rg:0.75, rp:0.62), weight of cormels per plant (rg:0.47, rp:0.37) and florets remaining open at a time in vase (rg:0.51, rp:0.30). So, more number of leaves means more plant height and spike length. Because of the increased photosynthesis leading to the availability of more photosynthates for the purpose. Similar correlation estimates were reported by Maurya et al. (2011) in gladiolus. Kumar et al., (2011)also reported positive and highly significant relationship of number of leaves per plant with length of the floret, yield of florets per plot, weight of florets per spike, flowering duration, number of spikes per $\mathrm{m}^{2}$, concrete recovery, spike length and rachis length. Gladiolusspike length had highly positive association with rachis length (rg:0.92, rp:0.88), floret diameter (rg:0.94, rp:0.0.74), spike diameter (rg:0.66, rp:0.50), duration of flowering (rg:0.71, rp:0.42), number of florets per spike (rg:0.89, rp:0.84), number of cormels per plant (rg:0.69, rp:0.65), diameter of corm (rg:0.48, rp:0.41), weight of corm (rg:0.44, rp:0.40), weight of cormels per plant (rg:0.20, rp:0.19), size index of corms (rg:0.41, rp:0.38), florets remaining open at a time in vase (rg:0.56, rp:0.33). At both genotypic and phenotypic levels it had negative correlation with number of spikes per plot (rg:-0.56, rp:-0.48), number of corms per plant (rg:-0.72, rp:-0.50), number of corms per plot (rg:-0.60, rp:-0.54) and florets remaining unopened (rg:-0.39, rp:-0.37).This is attributed to good supply of stored food materials from the corms having more weight to the developing spike. Similar results have been obtained by Ranchana et al. (2015) in tuberose. Spike length exhibited positive and significant associa- 
Dhara Singh et al. / J. Appl. \& Nat. Sci. 9 (2): 710 - 714 (2017)

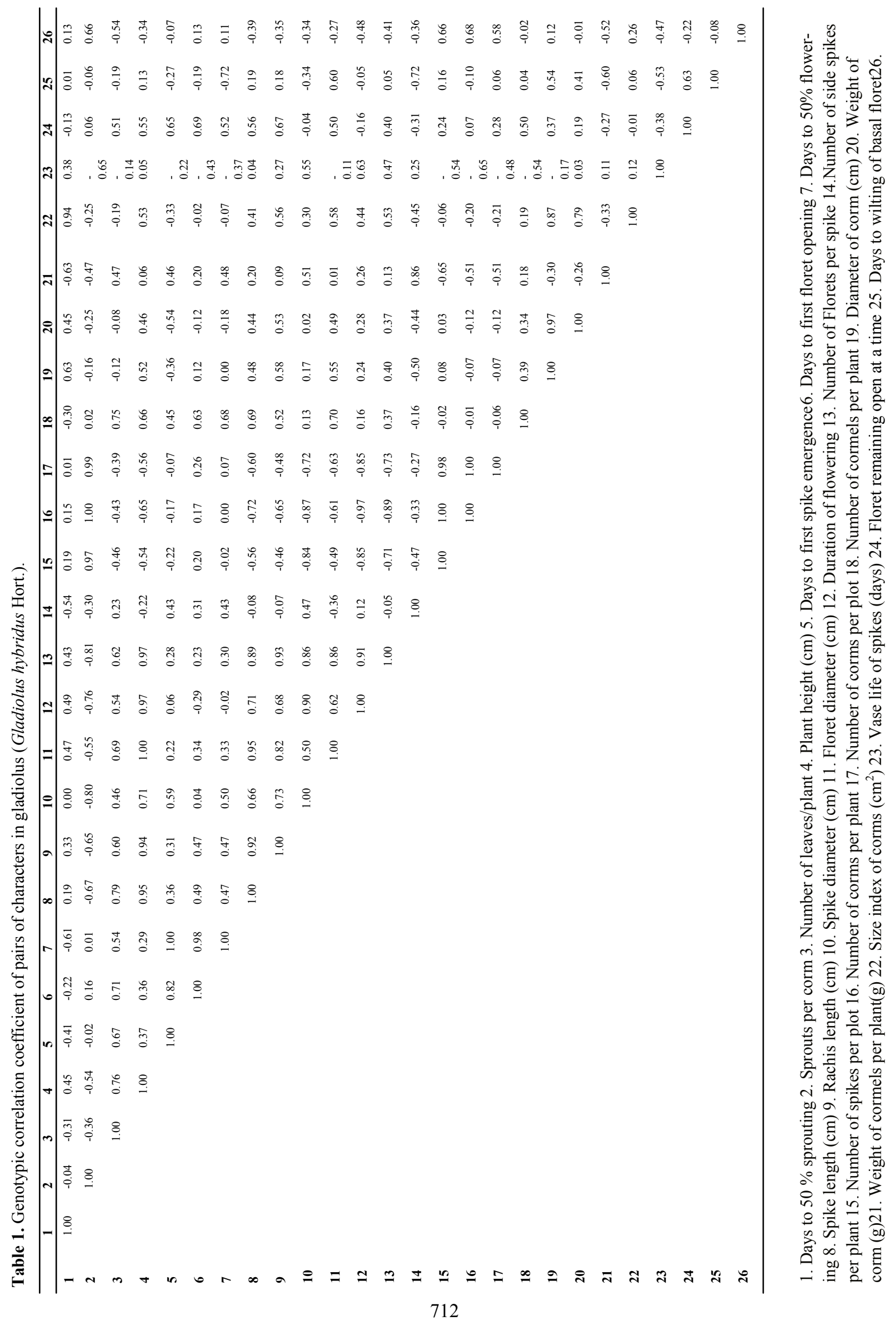


Dhara Singh et al. / J. Appl. \& Nat. Sci. 9 (2): 710 - 714 (2017)

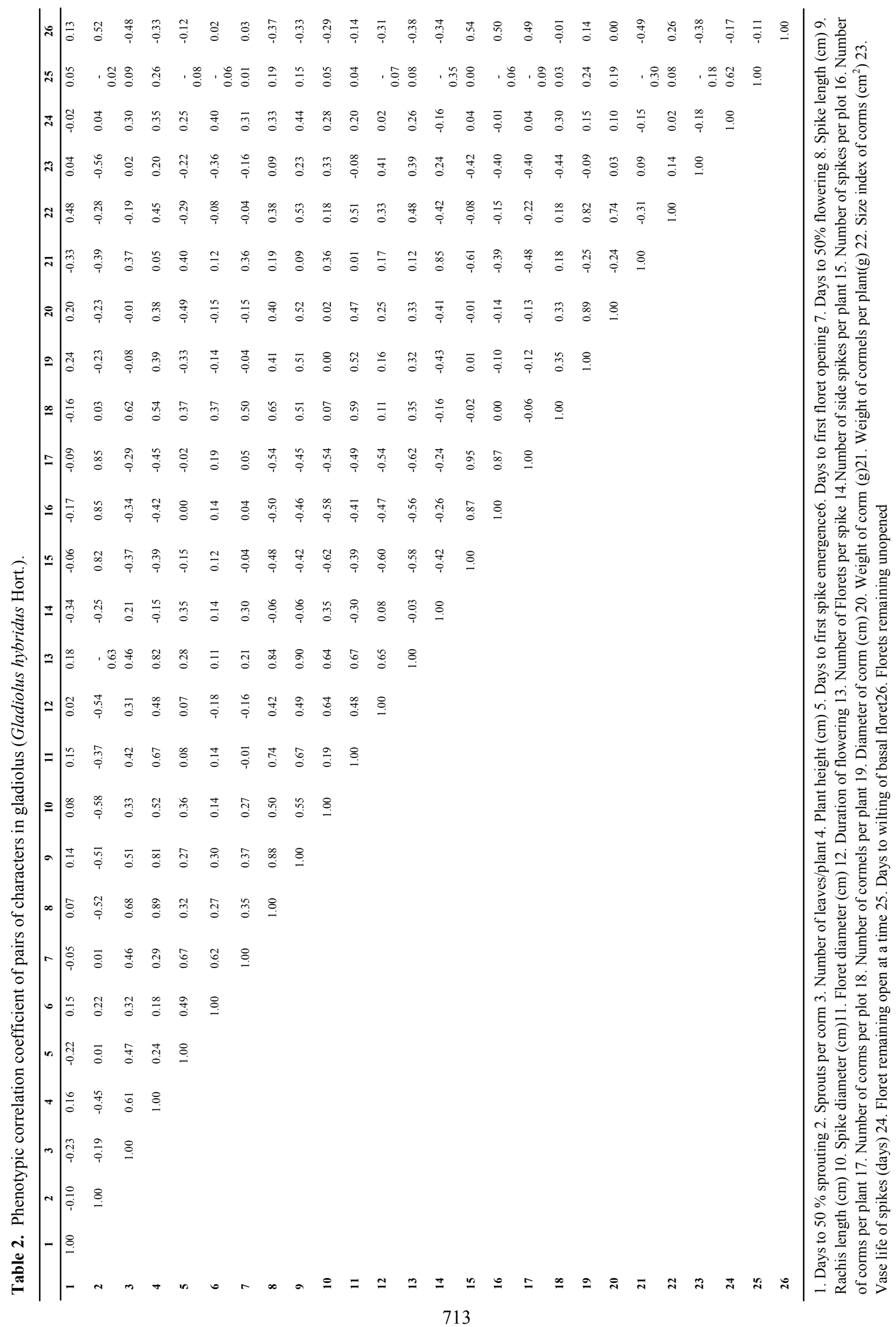


tion with rachis length, number of spikes per $\mathrm{m}^{2}$, concrete recovery, weight of florets per spike and yield of florets per plot. However, its association with number of florets/spike was negative at both phenotypic and genotypic levels. This is in consonance with the findings of Kumar and Kumar (2010) in snapdragon.

Yield is a complex trait, the expression of which depends on the action and multiple interactions of various components. Correlations measure the degree of association between the characters. In the present study, association of different cut flower characters with yield was studied and compared for superiority. Information on correlations between the important cut flower characters are of considerable help in the efficient selection programme. Correlations ensure simultaneous improvement in one or two or more variables and negative correlations bring out the need to obtain a compromise between the desirable traits. High correlations between two characters indicates that selection for the improvement of one character leads to the simultaneous improvement in the other character depending upon the magnitude of association between them (Gourishankarayya et al., 2005 and Pattanaik et al., 2015). The characters are considered to be independent when weak correlations exists, between them and selection for a character may not affect the other.

\section{Conclusion}

On the basis of findings of the present experiment the following conclusion may be drawn, most of the characters have higher genotypic correlation coefficent than phenotypic correlation coefficent. For yield (spike corm $^{-1}$ ) improvement through selection, much emphasis should be given on the characters like spike yield, corm yield, plant height, spike length days to $50 \%$ sprouting and number of florets per spike.

\section{REFERENCES}

Archana, B., Patil, A. and Patil, V. S. (2008). Studies on Genetic variability analysis in gladiolus hybrids. $J$. Orna. Hortic., 11(2): 121-126
Farhat, T. (2004). Plant characteristic and vase life of Gladiolus flowers as influenced by the preharvest and NPK application and postharvest chemical treatment. M.Sc. (Hons). Thesis, PMAS-AAUR

Fisher, R.A. and Yates, F. (1963).Statistical Tables for Biological, Agricultural andMedical Research, 6th Edition, Oliver and Boyd, Limited, Edinburgh.

Gourishankarayya, M. L., Hegde, L., Reddy, B. S. and Mulge, R. (2005).Correlation and path coefficient analysis in African marigold (Tagetuserecta L.). Karnataka J. Hortic., 1(3): 22-27

Kumar P., Mourya, R., Kumar, R., Binayak, C., Mer, R. and Mishra, D. S. (2011).Genitic variability and correlation studies in gladiolus hybridus under tarai condition. $J$. Orna. Hortic., 4(2): 140-146

Kumar, R. and Kumar, S. (2010). correlation studies in snapdragon (Antirrhinum majus L.). J. Orna. Hortic., 13(2): 133-137

Lepcha, B., M. C. Nautiyal and Rao, V. K. (2007). Variability studies in gladiolus under mid hill conditions of Uttarakhand. J. Orna. Hortic., 10(3): 169-172

Mandal, V.T. and Pradhan, S. (2013).Correlation and path coefficient analysis in tuberose. J. Crop Weed, 9: 44-49

Maurya, P.K., Binayak, R. K., Chakraborty, R. M. and Mishra, D. S. (2011).Genetic variability and correlation studies in gladiolus undertarai condition. Ann. Hortic., 4(2): $140-146$

Nazir, M., Dwivedi, V. K. and Bhat, K.L. (2003). Correlation studies in gladiolus over different environments. National Symposium on Recent Advances in Indian Floriculture, 12-14, P.280

Pattanaik, S., Paul, A.and Lenka, P. C. (2015). Genotypic and phenotypic variability and correlation studies in gladiolus. J. Crop Weed, 11(1):113-119

Ranchana, P., Kannan, M. and Jawaharlal, M. (2015). Assessment of Genetic and Correlation Studies in Single Types of Tuberose (Polianthes tuberosa) J. N.A.Ag.Sc. 33: 2.

Singh, D. and Kumar, S. (2008). Studies on genetic variability, heritability, genetic advance and correlation in marigold. J. Orna. Hortic., 11(1): 27-31

Singh N., (2009). Evaluation of hybrids and parents of Antirrhinum under Tarai condition, M.Sc. Thesis, Horticulture (Floriculture and Landscaping), G.B. Pant University of Agriculture and Technology, Pantnagar,104

Singh, R.K. and Chaudhary, B.D. (1979).Biometrical Methods in Quantitative Genetic Analysis, Kalyani Publications, Ludhiana. Singh, 